\title{
Proceedings from the 2016 JNC Board Meeting
}

\author{
Ami E. Iskandrian, MD, MACC, MASNC ${ }^{a}$ \\ a Division of Cardiovascular Diseases, Department of Medicine, University of Alabama at \\ Birmingham, Birmingham, AL
}

Received Nov 1, 2016; accepted Nov 1, 2016

doi: 10.1007/s12350-016-0727-5

Traditionally, the JNC holds one meeting at the time of the annual ASNC scientific sessions and one meeting at the time of ICNC scientific sessions. Each meeting is attended by the editor-in-chief (EIC), Managing Editor (ME) and many of the Associate Editors (AE), Guest Editors (GE), board members, representatives from ASNC, and the publisher. The two meetings are designed to allow members from within and outside the USA to attend at least one of the meetings. Our most recent meeting was on September 23, 2016 at the Boca Raton Resort \& Club, Boca Raton, FL, the site of the 2016 ASNC annual meeting.

The purpose of these meetings is twofold: to provide information and gather feedback. These meetings are generally well attended, the atmosphere is cordial, and the enthusiasm is palpable. We take the suggestions to our annual retreat with our publisher, held at the Springer offices in New York City on November 7, 2016, and attended by representatives chosen by the editors, the Publication committee, ASNC, and Springer.

The Journal continues to thrive, and the increase in our number of submissions is substantial. More than 50\% of these come from outside the United States, with the number of countries on the rise. We try very hard to select reviewers and authors who write editorials, review papers, debates, themes, etc., to reflect this diverse mix. Almost all accepted papers appear within 2-3 weeks online (and therefore can be cited); we regret any delays in printing them due to our increasing backlog, which is the price we pay for our success and growth. Our goal is simple: to make the Journal the most useful resource for those in the field of nuclear cardiac imaging. We wholeheartedly agree with Dr. Joseph Hill, the new editor-in-chief of Circulation, who said, "First, we will strive to further

Reprint requests: Ami E. Iskandrian, MD, MACC, MASNC, Division of Cardiovascular Diseases, Department of Medicine, University of Alabama at Birmingham, 318 LHRB/ 1900 University BLVD, Birmingham, AL, 35294; aiskand@uab.edu

J Nucl Cardiol 2017;24:1-3.

$1071-3581 / \$ 34.00$

Copyright (c) 2016 American Society of Nuclear Cardiology. enhance the Journal's impact on cardiovascular science and medicine and, ultimately, on the care of patients. We will redouble our efforts around impact: not impact factor, an oversimplified and overemphasized metric of scientific quality. Rather, we will focus on the impact of an article on advancing clinical practice or cardiovascular science. Does this paper inform my practice of cardiovascular medicine? Does it help me better care for my patients? Does the article advance the field with novel insights? Does it change the way we think?', (http://dx. doi.org/10.1161/CIRCULATIONAHA.116.023638).

We have categorized papers into various groups (alphabetically): abstracts/proceedings, brief report, cardiovascular literature search, debate article, editor's page, editorial, images that teach, international corner, letter to the editor, Review of the literature (a selection of recent, original research papers and cardiovascular disease in the literature), molecular imaging corner, nuclear cardiology literature search, original articles, review articles, and technologist corner. The decision for $>90 \%$ of total submissions occurs within 4 weeks, and we regret undue delays that are beyond our control. Along with other general cardiology journals, we have increased the number of editorials: a well-written editorial adds to the value of the paper it references, puts the results in perspective, and outlines future directions. In recognition of the efforts of the editorial writers, we have this year established the Ken Brown Award for Best Editorial in honor of the late Kenneth Brown, MD, the fifth president of ASNC, who succumbed to bone cancer in 2010. This is one of four awards given by the $\mathrm{JNC}$; the other three are the Zaret-Beller Award for the Best Reviewer, the Award for the Best Original Clinical Research paper, and the Award for the Best Original Basic/Technical Research paper. The winners of these awards in 2016 are shown in Figure 1. There were three independent committees involved in the selection process for each (Table 1).

Starting with the May 2016 issue, we are featuring a Spanish abstract translation of the lead article. We thank Erick Alexanderson, MD (a board member) and his 


\section{6 winners}
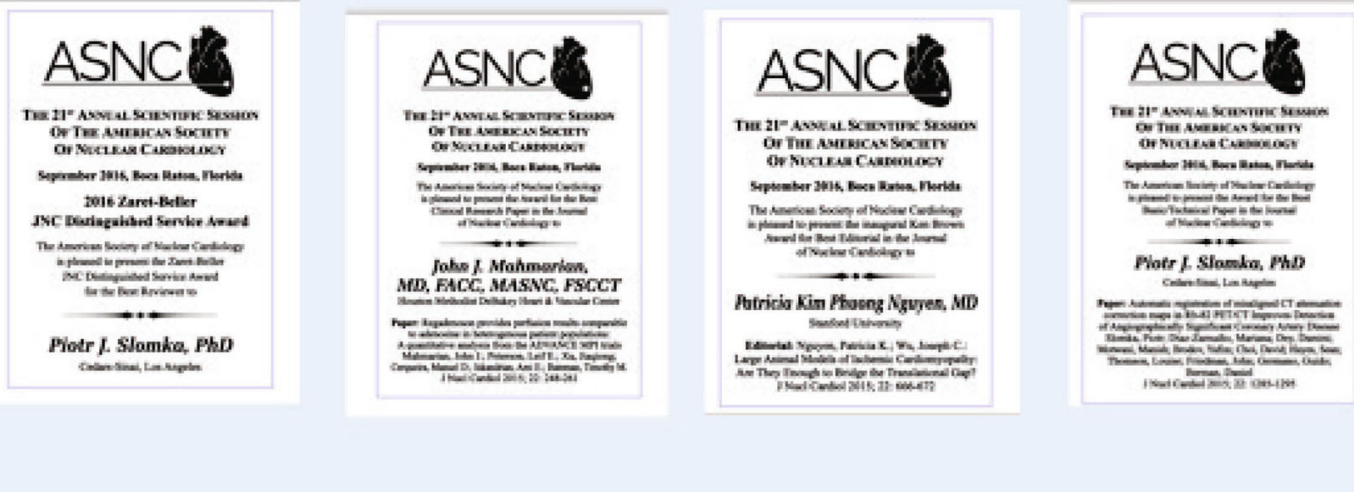

Figure 1. The 2016 JNC winners.

Table 1. The committee members to select the winners

\section{Committee for best papers Committee for best reviewer Committee for best editorial}

\author{
Ernest Garcia \\ Heinrich Schelbert \\ Jeroen Bax (Chair) \\ Manuel Cerqueira \\ Nagara Tamaki \\ Robert Gropler \\ Vasken Dilsizian \\ William Van Decker
}

Andrew Einstein (Chair)
Charity Morgan
Dainel Berman
Fadi Hage
Joseph Wu
Philipp Kaufmann
Rob Beanlands
Sharmila Dorbala

\author{
Alberto Cuocoloo \\ Jamieson M. Bourque \\ Leslee Shaw (Chair) \\ Mehran Sadeghi \\ Piotr Slomka \\ Prem Soman \\ Rami Doukky \\ Ron Blakstein \\ Frans Wackers
}

associates for their help in making this possible. Further, starting with the July 2016 issue, we are also including the Chinese translation of the abstract of the lead article. We thank Weihua Zhou, PhD (School of Computing, University of Southern Mississippi) and his associates for their help.

Additionally, we have started to provide powerpoint slides for many papers. These are prepared by the authors using a pre-specified template and reviewed by the editors. The response has been overwhelmingly positive and the quality superb. We believe these slides will serve a spectrum of useful educational purposes, and in time, we hope to make them available on the ASNC website as a valuable online resource for our subscribers.

We are also excited about our new audio interview feature, where our editors conduct interviews of authors of select papers that summarize the pertinent findings of a study.
Other new features include: What Is This Image? (unknown challenging image seeking interpretation which is then provided in more details together with the name of the winner!); "A Quick Glance of the Issue,' which is a summary of important articles appearing in the JNC; brief reports, debates, theme articles, ethical issues, and a selection of ACC/AHA/ESC abstracts.

We have also implemented other new features: Molecular Corner, Technologist Corner, International Corner, and comparison of selected American College of Cardiology/American Heart Association (ACC/AHA) versus European Congress of Cardiology (ESC) guidelines. You will see examples of all these new elements in the Journal. In an effort to raise awareness on the field of molecular imaging, we have published a list of sites in the United States and abroad that offer training in this modality, and we plan to update the list regularly.

The September issue heralded for the first time a series of articles on imaging in women. Our AEs Leslee 
Shaw and Sharmila Dorbala were the Guest Editors for this superb series that featured 8 papers. Of note, all authors of these papers were women as well.

The Mentoring at a Distance committee (Frans J. Th. Wackers, MD, Chair) has done a marvelous job helping authors improve their papers. With Dr. Wackers's permission, I am sharing with you a letter he received after helping a group of authors with their manuscript. The senior author wrote: "Thank you very much for your helpful support. Our manuscript is now much improved. I am going to resubmit the paper today. I was honored to work with you. I will never forget your kindness.' Dr. Wackers's response reflects our shared attitude toward this endeavor: "For those who really are willing to put in the time and effort, this mentorship is a unique and very rewarding experience."

The quote, arts, photos, and poems that appear in the front of the Journal have by now become a staple. Thank you for your contributions and enthusiasm.
At the ASNC meeting in September 2016 in Boca Raton, FL, we had the first meeting of the Molecular Corner with the hope of staring a dialog with industry scientists on how best to move the field to the next level. I will write more on this topic in the future.

Finally, this year, we are pleased to announce that we have a Publication Committee of respected leaders who will provide oversight and advice on critical issues. The committee is comprised Dan Berman, MD (Chair), Rory Hachamovitch MD, Eliana Reyes MD, Gary Heller MD, and Frans Wackers MD.

I'm grateful to all AEs, GEs, ME, ASNC leadership and staff, authors, reviewers, publisher, and our various committees for their continued support and devotion. Together, our goal is to continue to improve the Journal and make it worthy of our worldwide readership community. As always, I welcome your feedback. 